\title{
Deaths and tumours among workers grinding stainless steel: a follow up
}

\author{
K Jakobsson, Z Mikoczy, S Skerfving
}

\begin{abstract}
Objective-To study cause specific mortality and cancer morbidity in workers exposed to the dust of grinding materials, grinding agents, and stainless steel, especially with regard to a possibly increased risk of respiratory, stomach, and colorectal cancer.
\end{abstract}

Methods-Retrospective cohort study, using reference cohorts of blue collar workers and population rates for comparison. The exposed cohort comprises workers with at least 12 months employment time at two plants, producing stainless steel sinks and saucepans $(n=727)$. Also, reference cohorts of other industrial workers $(n=3965)$ and fishermen $(n=8092)$ were analysed. The observation period began 15 years after the start of employment. Standardised mortality or incidence ratios (SMRs, SIRs; county reference rates) were calculated for cause-specific mortality between 1952 and 1993, and for cancer morbidity between 1958 and 1992.

Results-In the exposed cohort, overall mortality, cardiovascular mortality, and all malignant mortality and morbidity were slightly lower than expected. Also, the risk estimates for cancer in the upper and lower respiratory tracts and for stomach cancer were lower than expected. There was an increase of morbidity from colon cancer, which was explained by an excess of tumours in the sigmoid part only. Here, the risk estimates were higher in workers with long employment time (1-14 years: four observed cases, SIR 1.7, 95\% confidence interval (95\% CI) 0.4 to 4.5; $\geqslant 15$ years: three observed cases, SIR $4.3,95 \%$ CI 0.9 to 13 ) and the increased risk was especially pronounced among those first employed before 1942. A slight nominal excess of rectal cancers (nine observed cases, SIR 1.4, 95\% CI 0.6 to 2.6 ), and a significant excess of prostate cancer morbidity (36 observed cases, SIR 1.7, 95\% CI 1.2 to 2.4) were found. These risk estimates did not, however, increase with employment time.

Conclusions-The finding of an increased risk of cancer in the sigmoid part of the colon, which was not found in the reference cohorts, and with indication of a relation between duration of employment and response, is consistent with a causal relation. The limited size of the exposed cohort makes a detailed exposure-response analysis unstable, and the confi- dence limits are wide. Albeit slightly raised, the risk estimate for rectal cancer in the exposed cohort was not different from the estimate among the other industrial workers.

(Occup Environ Med 1997;54:825-829)

Keywords: colon; rectum; prostate; stainless steel dust

The manufacturing of stainless steel products, including grinding, finishing, and polishing, causes exposure to several agents with potentially disease inducing properties. The metal exposure includes chromium and nickel, of which some forms are established carcinogens. ${ }^{1}$ Grinding is often done with hard materials, such as silicon carbide and aluminium oxide, glued ceramically or by phenol-formaldehyde resin on ribbons or plates. Also, oils and waxes are used for polishing. A previous analysis of a cohort of workers grinding stainless steel indicated an increased risk for colorectal cancer. ${ }^{2}$ An increased risk for cancers in the gastrointestinal tract has also been reported among workers producing grinding materials, ${ }^{3}$ stainless steel polishers, ${ }^{4}$ and jewellery polishers. ${ }^{5}$

However, there are reasons to consider cancer in the different parts of the gastrointestinal tract separately. ${ }^{6-8}$ There are obvious variations by sex, age, and social class in the incidence of cancer of the stomach, colon, and rectum, ${ }^{9} 10$ which may partly be mediated by differences in diet, body mass, and physical activity. The present follow up of the cohort of workers grinding stainless steel thus entails comparisons, not only with the general population, but also with reference populations consisting of other industrial workers, and of outdoor manual workers, to give better comparability on the group level.

\section{Material and methods}

EXPOSED COHORT

The cohort, the plants where stainless steel sinks and saucepans were produced, and some data on exposure were previously described in detail. ${ }^{2}$ Production in the first plant started in 1927; in 1961 the production was transferred to a second plant in a nearby town. All men, employed at least 12 months during the period 1927 to 31 March 1981 , were included in the present follow up. There were altogether 823 enlisted men, of which 23 could not be fully identified. Twelve men had died or emigrated before 1952, which is the start of the follow up. Until the end of 1993, none of the remaining 
788 men were lost to follow up. The median year of birth in the cohort was 1920 (25 and 75 percentiles 1912 and 1934, respectively). The observation period began 15 years after start of employment. Thus, in the mortality analysis the final cohort included 727 men, in the morbidity analysis 719 men.

The workers were exposed to metal dust (stainless steel; $18 \%$ nickel $(\mathrm{Ni}), 8 \%$ chromium (Cr)) and dust from the abrasives (including silicon carbide, aluminium oxide, amorphous silicon dioxide, clay, and phenol-formaldehyde resins). Cutting fluids were not used. Oils and waxes were used during the polishing. The dust levels in the plant were probably high before the 1950s; no dust measurements are, however, available. Later, the ventilation gradually improved, and automation expanded. Measurements in the second plant in the period 1975-80 indicated dust levels at grinding of $0.7-7.3 \mathrm{mg} / \mathrm{m}^{3}(3-10 \% \mathrm{Cr}, 2-5 \% \mathrm{Ni})$, and at brushing and polishing $1.6-16 \mathrm{mg} / \mathrm{m}^{3}(1 \% \mathrm{Cr}$, $0.5 \% \mathrm{Ni}$ ). The $\mathrm{Cr}$ was mainly metallic. The metal particles were respirable only to a minor degree.

A crude categorisation of workers into exposure level was made, based on notations in the plant records of jobs held. Grinders $(n=249)$, brushers/polishers $(n=105)$, and welders $(n=66)$ were assumed to have been the most heavily exposed workers.

\section{CONTROL COHORT}

A detailed description of the reference cohorts, including both manual workers from industrial settings and outdoor workers, is given elsewhere. ${ }^{11}$ Male industrial workers with various chemical exposures, but with no appreciable exposure to dust, which is persistent in the intestinal tract after inhalation and swallowing - for example, metal dust, mineral dust and mineral fibres, were selected as one of the comparison groups. Exposure to other types of inorganic or organic dust may, however, have occurred, as well as exposure to various suspected carcinogens. The cohort includes workers from a plant synthesising many organic chemical products $(n=313)$, workers from a fertiliser plant producing superphosphate $(n=1201)$, leather workers $(n=1156)$, workers producing polyurethane foam $(n=705)$, abattoir workers $(n=100)$, workers from a wool and polyester textile plant $(n=148)$, and sugar refinery workers $(n=342)$, altogether 3965 blue collar workers (figures refer to workers included when morbidity was studied). The median year of birth in the cohort of industrial workers was 1924 (25 and 75 percentiles 1912 and 1940, respectively).

Male members of fishermen's organisations from the east and west coasts of Sweden formed another comparison group, consisting of 8078 fishermen. The median year of birth was 1922 (25 and 75 percentiles 1909 and 1938).

CAUSE OF DEATH AND TUMOUR MORBIDITY

Information on cause of death from 1952 and onwards, coded according to the eighth revision of the international classification of diseases (ICD-8), was obtained from Statistics Sweden. In $35 \%$ of the deceased men in the exposed cohort, death certificates were based on clinical or forensic necropsy. The corresponding figure for the industrial workers was $44 \%$, for the fishermen $37 \%$.

Information on up to at most two tumours diagnosed from 1958 and onwards, coded according to ICD-7, was obtained from the National Swedish Tumour Registry. Histological or cytological examinations had been performed in $97 \%$ of the tumours in the exposed cohort, according to registry information. The corresponding figure for the industrial workers was $95 \%$, for the fishermen $92 \%$.

The end of follow up in the exposed cohort was 1992 for morbidity, 1993 for mortality. For the subgroups in the reference cohorts the end of follow up varied between 1987 and 1989.

\section{RISK ESTIMATES}

Expected mortality for the period between 1952 and 1993 or the appropriate period was calculated using cause, calendar year, and fiveyear age group specific mortalities. These rates were calculated from death and population counts obtained from Statistics Sweden. Date of death or emigration were used as individual end points, whichever occurred first. Similarly, yearly cancer morbidity rates during the period between 1958 and 1992 (or the appropriate period) were obtained from the National Swedish Tumour Registry. Date of death, tumour diagnosis, or emigration were used as individual end points. County rates, as well as national rates, were available for both mortality and morbidity.

\section{ANALYSIS}

Standardised mortality rates (SMRs), cause specific standardised incidence rates (SIRs), and $95 \%$ confidence intervals (95\% CIs) were calculated by treating the observed number as a Poisson variable, or a normal variable if the observed value was greater than 15. Expected values for mortality and morbidity are based on the relevant county rates for each cohort or subcohort. The term "significant" corresponds to the limits of the $95 \%$ CI for SMR, or SIR, that do not include 1.00. Exposure (duration of employment)-response relations were assessed by analyses of SIRs over strata, based on the individual cumulated time. Thus, each individual contributed person-years successively to each stratum. ${ }^{12} 13$

\section{Results}

MORTALITY

In the exposed cohort, the overall mortality (292 observed deaths, SMR 0.9, 95\% CI 0.81.1 ), as well as all malignant (61 observed deaths, SMR 0.8, 95\% CI 0.6-1.1) and all cardiovascular mortality (158 observed deaths, SMR 0.9, 95\% CI 0.7-1.1), was nominally lower than in the general population. The mortality pattern was similar among the grinders/polishers/welders. The corresponding SMRs among the industrial workers were 1.0 , 
Table 1 Tumour morbidity 1958-92 in a cohort of workers grinding stainless steel and in control workers (a minimum employment time of one year was required: the observation period began 15 years after the start of employment)

\begin{tabular}{|c|c|c|c|c|c|c|c|c|c|c|c|c|c|}
\hline \multirow[b]{3}{*}{ Tumour } & \multirow[b]{3}{*}{$I C D-7$} & & & & & \multicolumn{8}{|c|}{ Control cohorts } \\
\hline & & \multicolumn{4}{|c|}{ Exposed cohort $(n=719)$} & \multicolumn{4}{|c|}{ Industrial workers $(n=3965)$} & \multicolumn{4}{|c|}{ Fishermen $(n=8078)$} \\
\hline & & $O$ & $E$ & $S I R$ & $95 \% C I$ & $O$ & $E$ & SIR & $95 \% C I$ & $O$ & $E$ & SIR & $95 \% C I$ \\
\hline All malignat tumours & $140-209$ & 112 & 119 & 0.9 & 0.7 to 1.2 & 478 & 435 & 1.1 & 1.0 to 1.2 & 832 & 856 & 1.0 & 0.9 to 1.1 \\
\hline Oropharyngeal & $141-148$ & 3 & 1.8 & 1.6 & 0.3 to 4.8 & 13 & 8.2 & 1.6 & 0.8 to 2.7 & 16 & 14.8 & 1.1 & 0.6 to 1.8 \\
\hline Stomach & 151 & 8 & 9.6 & 0.8 & 0.3 to 1.7 & 33 & 30.4 & 1.1 & 0.7 to 1.6 & 50 & 57 & 0.9 & 0.6 to 1.2 \\
\hline Colon & 153 & 12 & 8.3 & 1.4 & 0.7 to 2.6 & 29 & 32.8 & 0.9 & 0.6 to 1.3 & 68 & 70.7 & 1.0 & 0.7 to 1.3 \\
\hline Rectum & 154 & 9 & 6.7 & 1.4 & 0.6 to 2.6 & 32 & 25.0 & 1.3 & 0.8 to 1.9 & 44 & 43.6 & 1.0 & 0.7 to 1.4 \\
\hline Pancreas & 157 & 3 & 3.7 & 0.8 & 0.1 to 2.4 & 15 & 14.5 & 1.0 & 0.5 to 1.8 & 34 & 29 & 1.2 & 0.8 to 1.7 \\
\hline Sinonasal & 160 & 0 & 0.5 & 0.0 & 0.0 to 8.0 & 3 & 1.1 & 2.7 & 0.5 to 7.8 & 4 & 2.2 & 1.8 & 0.4 to 4.6 \\
\hline Larynx & 161 & 1 & 1.4 & 0.7 & 0.0 to 3.9 & 4 & 5.6 & 0.7 & 0.1 to 1.9 & 6 & 8.6 & 0.7 & 0.2 to 1.6 \\
\hline Primary lung & $1620-1621$ & 7 & 12.4 & 0.6 & 0.2 to 1.2 & 48 & 45.0 & 1.1 & 0.7 to 1.5 & 72 & 69.7 & 1.0 & 0.8 to 1.4 \\
\hline Prostate & 177 & 36 & 21.2 & 1.7 & 1.2 to 2.4 & 105 & 87.0 & 1.2 & 0.9 to 1.5 & 200 & 197 & 1.0 & 0.8 to 1.2 \\
\hline Renal & 1800 & 5 & 3.8 & 1.3 & 0.4 to 3.2 & 15 & 13.1 & 1.1 & 0.6 to 1.9 & 22 & 25.2 & 0.9 & 0.5 to 1.4 \\
\hline Uroepitheal & 1801,181 & 5 & 10.0 & 0.5 & 0.1 to 1.2 & 42 & 36.3 & 1.2 & 0.8 to 1.6 & 45 & 59.7 & 0.7 & 0.5 to 1.1 \\
\hline Lymphoma, myeloma & $200-203$ & 3 & 5.7 & 0.5 & 0.1 to 1.6 & 22 & 20.8 & 1.1 & 0.6 to 1.7 & 41 & 41.6 & 1.0 & 0.7 to 1.4 \\
\hline
\end{tabular}

$\mathrm{O}=$ observed; $\mathrm{E}$ = expected; $\mathrm{SIR}$ = standardised incidence ratio.

1.1 , and 1.0 , among the fishermen $0.9,0.9$, and 0.9 (all 95\% CIs including 1.0), respectively.

\section{MORBIDITY}

In the exposed cohort, there were 112 malignant tumours among 719 men (table 1). There were nominally clear deficits of lung cancer (SIR 0.6), laryngeal cancer (SIR 0.7), uroepithelial cancer (SIR 0.5), and pancreatic cancer (SIR 0.8). This finding contrasted with the observations for other industrial workers, among whom these tumours were nominally in slight excess. The fishermen had a pattern resembling the general population. The risk for stomach cancer was also nominally lower (SIR 0.8) than expected in the exposed cohort. Among the grinders/polishers/welders, the findings for the above mentioned cancers were similar to those in the unrestricted exposed cohort.

For the colorectal cancers, the site specific morbidity was analysed. There was an increase of tumours only in the sigmoid part, overall SIR 2.3 (seven observed cases, $95 \%$ CI 0.9 to 4.9). In the subgroup of grinders/polishers/ welders the same subsite pattern emerged. The risk estimate was higher in workers with long employment time; for $\geqslant 15$ years the SIR was 4.3 (three observed cases, $95 \%$ CI 0.9 to 13 ) (table 2). A slight nominal excess of rectal cancers (nine observed cases, SIR 1.4, 95\% CI 0.6 to 2.3) was also found, however not with increasing SIRs with rising employment time.
Review of the job histories of all cases of colorectal cancer did not disclose any clustering of certain job titles. All of them had started their employment before 1963 (median 1935).

As the follow up of tumours starts in 1958, the subgroup of men first employed before 1942 inevitably has a longer induction-latency time, as well as a longer follow up period than those employed later. To eliminate this inclusion and observation bias, which theoretically might bias the risk estimate among these men upwards, two subgroups of workers were created, having similar ranges of these indices. The first group included workers first employed between 1927 and 1942, who were followed up during the period 1958 to 1976 . The median duration of employment time was 10 years. The second group included workers, first employed between 1943 and 1958, who were followed up during the period between 1974 and 1992. The median duration of employment time was nine years. For sigmoid cancer, a pronounced effect of calendar year of first employment was found, with SIR 10 (four observed cases, $95 \%$ CI 2.7 to 26 ) in the first group, compared with SIR 2.3 (two observed cases, $95 \%$ CI 0.2 to 8.5 ) in the second group. A similar, but not so pronounced pattern was also found for rectal cancer, with SIR 3.5 (four observed cases, $95 \%$ CI 0.9 to 9.0 ) and SIR 1.1 (two observed cases, 95\% CI 0.1 to 3.6), respectively.

Table 2 Site specific colorectal cancer morbidity 1958-92 in a cohort of workers grinding stainless steel and in control workers (a minimum employment time of one year was required: the observation period began 15 years after the start of employment)

\begin{tabular}{|c|c|c|c|c|c|c|c|c|c|c|c|c|c|c|c|c|c|}
\hline \multirow[b]{3}{*}{ Tumour } & \multirow[b]{3}{*}{$I C D-7$} & \multicolumn{8}{|c|}{ Exposed cohort } & \multicolumn{8}{|c|}{ Control cohorts } \\
\hline & & \multicolumn{4}{|c|}{ Employed 1-14 y $(n=537)$} & \multicolumn{4}{|c|}{ Employed $\geqslant 15$ y $(n=182)$} & \multicolumn{4}{|c|}{ Industrial workers $(n=3965)$} & \multicolumn{4}{|c|}{ Fishermen $(n=8078)$} \\
\hline & & $O$ & $E$ & SIR & $95 \% C I$ & $O$ & $E$ & SIR & $95 \% C I$ & $O$ & $E$ & SIR & $95 \% C I$ & $O$ & $E$ & $S I R$ & $95 \% C I$ \\
\hline \multicolumn{2}{|l|}{ Caecum and colon } & & 2.3 & 0.4 & 0.0 to 2.5 & 0 & 0.6 & 0.0 & 0.0 to 6.0 & 3 & 9.1 & 0.3 & 0.0 to 1.0 & 23 & 22.2 & 1.0 & 0.6 to 1.6 \\
\hline Colon transversum & & & & & & & & & & & & & & & & & \\
\hline including flexure & 1531 & 1 & 0.6 & 1.8 & 0.0 to 10 & 0 & 0.2 & 0.0 & 0.0 to 24 & 3 & 4.2 & 0.7 & 0.1 to 2.1 & 9 & 8.9 & 1.0 & 0.4 to 2.0 \\
\hline Colon descendens & 1532 & 0 & 0.3 & 0.0 & 0.0 to 11 & 0 & 0.1 & 0.0 & 0.0 to 38 & 1 & 1.8 & 0.5 & 0.0 to 3.1 & 2 & 3.2 & 0.6 & 0.0 to 2.3 \\
\hline Colon sigmoideum & 1533 & 4 & 2.3 & 1.7 & 0.4 to 4.5 & 3 & 0.7 & $4.3^{\star}$ & 0.9 to 13 & 13 & 12.3 & 1.0 & 0.5 to 1.8 & 19 & 25.8 & 0.7 & 0.4 to 1.2 \\
\hline \multicolumn{18}{|l|}{ Colon, multiple or not } \\
\hline specified & $1538-1539$ & 2 & 0.9 & 2.3 & 0.2 to 8.2 & 1 & 0.2 & 4.2 & 0.1 to 24 & 9 & 4.5 & 2.0 & 0.9 to 3.3 & 13 & 10.2 & 1.3 & 0.6 to 2.2 \\
\hline Rectum (anus included) & 154 & 7 & 5.2 & 1.3 & 0.5 to 2.8 & 2 & 1.4 & 1.4 & 0.1 to 5.0 & 32 & 25.0 & 1.3 & 0.8 to 1.9 & 44 & 43.6 & 1.0 & 0.7 to 1.4 \\
\hline
\end{tabular}

$\star \mathrm{P}=0.2$; test for trend $(1-14 \mathrm{y} v \geqslant 15 \mathrm{y})$.

$\mathrm{O}=$ observed; $\mathrm{E}=$ expected; $\mathrm{SIR}=$ standardised incidence ratio. 
Among the other industrial workers, as in the exposed cohort, a decreased incidence of cancer in the proximal part of the colon was found (ICD-7 1530-1531; six observed cases, SIR $0.4,95 \%$ CI 0.1 to 1.0 ), whereas the fishermen did not differ from the general population in this respect. In both reference groups, the risk for cancer in the sigmoid part of the colon was close to, or lower than, the risk in the general population. Just as in the exposed cohort, a slight nominal increase of rectal cancer was found among the other industrial workers.

In the exposed cohort, there was no excess of sinonasal or laryngeal cancer. However, there were three workers ( $v 1.3$ expected) with oropharyngeal cancer, all with more than five years of employment, starting in the 1930s.

A significant excess of morbidity from prostate cancer (SIR 1.7) occurred in the exposed cohort. Overall mortality from prostate cancer, reflecting the aggressive tumours, was, however, not significantly increased (12 observed cases, SMR 1.3, 95\% CI 0.6 to 2.2). The SIRs did not increase with increasing employment time (1-14 years: 29 observed cases, SIR 1.7, $95 \%$ CI 1.1 to 2.6 ; $\geqslant 15$ years: seven observed cases, SIR $1.5,95 \%$ CI 0.6 to 3.2). Also, the risk estimates for the above described subgroups with different calendar year of first employment were similar (between 1927 and 1942: five observed cases, SIR 2.6, 95\% CI 0.8 to 6.1; between 1943 and 1958: 13 observed cases, SIR 2.1, 95\% CI 1.1 to 3.6).

\section{Discussion}

In studies of occupational cohorts, the selection of suitable populations for comparisons is of importance. For gastrointestinal cancer, several well known risk factors-such as diet, body mass, and physical activity-are linked to socioeconomic status. Information on an individual level is, however, almost impossible to obtain in a retrospective occupational cohort. Therefore, we also made comparisons with reference populations consisting of other industrial workers and manual workers to gain better comparability in these factors, which may act as confounders. It has to be remembered that these reference populations in no way are "unexposed"; they are assembled from previous cohorts studied at our department because of exposure to various potential carcinogens. They were, however, not exposed to dusts, which are supposed to be persistent in the body after inhalation.

For all cohorts, the loss of follow up was very limited. Comparability between cohorts as to the validity of tumour diagnosis was supposed to be good, as the proportions of tumours confirmed by histology or cytology evaluations were similar. The difference between the cohorts for year of birth was small, at most five years (median), the exposed cohort being older. Thus, a cohort effect could not reasonably bias the results.

There are geographical differences in incidences of stomach $^{14}$ and colorectal ${ }^{10}{ }^{14}$ cancer in Sweden. Around $80 \%$ of the industrial workers in the reference cohorts had worked in plants situated in the most southern part of Sweden, just as in the exposed workers. The fishermen, however, came from all the coastal areas. Thus, we used regional reference rates for comparisons. When the analyses were repeated with national comparison rates (results not given), only minor differences in the risk estimates were found.

A "healthy worker selection" is often, but not always, found in industrial cohorts. ${ }^{15}$ In the exposed cohort, the reduced overall mortality, including cardiovascular and tumour mortality, as well as reduced tumour morbidity, is probably explained by such selection. Information on individual smoking habits is not available, but there was a smoking prohibition in the first plant until the 1950s. The observed deficit of smoking-related cancers (lung, larynx, uroepithelial, pancreas), which was not found among the other industrial workers, is in favour of a low tobacco consumption in the cohort.

In the previous analysis of the exposed cohort, ${ }^{2}$ the most remarkable finding was an excess of cancer in the colon and rectum. The present follow up shows that this increase was confined to tumours in the sigmoid part of the colon, and to a lesser degree in the rectum This accords with a case-referent study among urban men younger than 45 years of age in whom colorectal cancers were subdivided as to site. In these men tumours in the sigmoid and rectum were associated with metal dust exposure, by contrast with proximally located tumours. ${ }^{16}$ Also, there are several reports of an increase of colon or rectal cancer associated with exposures to metal dust and cutting oils. ${ }^{17-20}$

A study that used linked information from the cancer registry and information on occupation from the 1960 population census shows that Swedish blue collar workers had a lower incidence of cancer in both the right and the left part of the colon, compared with white collar workers and self employed men. ${ }^{10}$ The findings among the other industrial workers and the fishermen are in accord with these findings.

An increased risk of stomach cancer has been found in workers producing grinding materials, ${ }^{3}$ albeit not consistently, ${ }^{21}$ in metal polishers, ${ }^{4}$ and in metal workers using cutting fluids. ${ }^{181922}$ As in the previous analysis of this cohort, we found a deficit of stomach cancer, comparing both with the general population and the other industrial workers. The assumed relatively low smoking may, at least partly, explain our findings.

Some Ni compounds and $\mathrm{Cr}$ (VI) are established human respiratory carcinogens. In humans there is, however, inadequate evidence for the carcinogenicity of metallic $\mathrm{Ni}, \mathrm{Ni}$ alloys, and metallic $\mathrm{Cr} .{ }^{1}$ Formaldehyde, which in animal experiments causes nasal cancer, ${ }^{23}$ may be released by the heat from the resin of the grinding plates. We found no excess of sinonasal cancer, laryngeal cancer, or lung cancer. However, there were a few oropharyngeal tumours occurring among workers employed in the 1930s. Previously, in a case-control study of oropharyngeal and hypopharyngeal cancer, 
exposure to iron and steel dust was associated with an increased risk of cancer. ${ }^{24}$

Prostate cancer is usually not regarded as being associated with occupational risk factors, ${ }^{25}{ }^{26}$ and tends to be somewhat more common in higher socioeconomic strata. However, there are indications that metal workers may have a slightly increased risk. ${ }^{28}$ The finding among metal workers of a modest positive association between prostate cancer and the use of straight cutting oils is also worth mentioning. ${ }^{22}$ For metal exposure, there is weak evidence that exposure to $\mathrm{Cd}$ may be of importance. ${ }^{29}$ An association with $\mathrm{Ni}$ or $\mathrm{Cr}$ exposure was not found in a Canadian case-referent study $^{28}$ and not among metal workers within the construction industry. ${ }^{30} \mathrm{~A}$ significant excess of prostate cancer was found in our exposed cohort, but the risk estimates did not increase with employment time, thus not supporting a causal relation between exposure and risk.

In conclusion, our findings from the present small cohort of workers exposed to metal dust and dust from grinding agents indicate that the historical working conditions conveyed an increased risk for cancer in the sigmoid part of the colon. It is not likely that our findings in the exposed cohort can be attributed to confounding by a tentative multifactorial "industrial worker" or "manual worker" effect. The risk estimate was higher in subcohorts with long employment time, and in subcohorts of workers with first employment early in the production period, when dust exposure and other working conditions are likely to have been worse than later on. Both findings are consistent with a causal relationship. The limited size of the cohort, however, precludes a more detailed exposure-response analysis. Albeit slightly raised, the risk estimate for rectal cancer was not different from the estimate among the other industrial workers.

Also, this study, as well as findings from a previous study among workers exposed to cement and asbestos cement dust, ${ }^{11}$ shows the necessity to separate cancer in the different subsites within the gastrointestinal tract, as the morbidity pattern need not to be uniform. Analysis of colorectal cancer risk by subsite may prove a meaningful approach to the study of cancer aetiology. Further, findings in the reference cohorts of manual workers indicate that there might be an "industrial worker effect" which influences the risk for colorectal cancer, a finding which underlines the necessity of careful selection of reference populations when occupational factors are studied.

The original cohort was assembled by the late Dr BG Svensson. The exposure classification was performed by Assistant Professor Bengt Ákesson. We thank Ms Elisabeth Jonsson and the staff at the company for assistance in the updating of the cohort and Professor Lars Hagmar for valuable comments. The study was supported by the Swedish Work Environment Fund and the Faculty of Medicine, Lund University.

1 International Agency for Research on Cancer. Chromium, nickel and welding. Lyon: IARC, 1990:49-445. (IARC Monogr Eval Carcinog Risks Hum 49.)

2 Svensson BG, Englander V, Ákesson B, Attewell R, Skerfving $S$, Ericson $\AA$, Möller T. Deaths and tumours among workers grinding stainless steel. Am 7 Ind Med 1989;15:51-9.

3 Wegman DH, Eisen E. Causes of death among employees of a synthetic abrasive product manufacturing company. $f$ a synthetic abrasive product

4 Järvholm B, Thiringer G, Axelson O. Cancer morbidity among polishers. Br f Ind Med 1982;39:196-7.

5 Sparks PJ, Wegman DH. Cause of death among jewelry workers. F Occup Med 1980;22:733-6.

6 Weisburger JH, Wynder EL, Horn CL. Nutritional factors and etiologic mechanisms in the causation of gastrointestinal cancers. Cancer 1982;50:2541-9.

7 Beart RW, Melton LJ, Maruta M, Dockerty MB, Frydenberg HB, O'Fallon MW. Trends in right and left-sided colon cancer. Dis Colon Rectum 1983;26:393-8.

8 Bufill JA. Colorectal cancer: evidence for distinct genetic categories based on proximal or distal tumor location. Ann Int Med 1990;113:779-88.

9 Vågerö D, Persson G. Occurrence of cancer in socioeconomic groups in Sweden. Scand $\mathcal{F}$ Soc Med 1986;14: $151-60$.

10 Gerhardsson M, Steineck G, Norell SE. Colorectal cancer in Sweden. A descriptive epidemiologic study. Acta Oncol 1990;29:855-61.

11 Jakobsson K, Albin M, Hagmar L. Asbestos, cement, and cancer in the right part of the colon. Occup Environ Med 1994;51:95-101.

12 Breslow NE, Lubin JH, Marek P, Langholtz B. Multiplicative models and cohort analysis. $\mathcal{F} \mathrm{Am}$ Stat Assoc 1983;78:1-12.

13 Swaen GMH, Volovics A. Investigating dose-response relations in occupational mortality studies: something to keep in mind. Br f Ind Med 1987;44:642-4.

14 National Board of Health and Welfare. The Cancer Registry. Cancer Incidence in Sweden. Stockholm, Allmänn Förlaget (published annually)

15 Monson R. Observations on the healthy worker effect. $f$ Occup Med 1986;28:425-33.

16 Peters RK, Garabrant DH, Yu MC, Mack TM. A case-control study of occupational and dietary factors in colorectal cancer in young men by subsite. Cancer Res 1989;49:5459-68.

17 Robinson C, Waxweiler RJ, McCammons CS. Pattern and model makers, proportionate mortality 1972-8. Am f Ind Med 1980;1:159-65.

18 Park RM, Wegman DH, Silverstein MA, Maizlish NA, Mirer FE. Causes of death among workers in a bearing manufacturing plant. Am $\mathcal{F}$ Ind $M e d$ 1988;13:569-80.

19 Silverstein M, Park R, Marmor M, Maizlish N, Mirer F. Mortality among bearing plant workers exposed to metalworking fluids and abrasives. $\mathcal{F}$ Occup Med 1988:30: 706-14.

20 Tolbert PE, Eisen EA, Pothier LJ, Monson RR, Hallock MF, Smith TJ. Mortality studies of machining-fluid exposure in the automobile industry. Scand $f$ Work Environ Health the automobile

21 Edling C, Järvholm B, Andersson L, Axelson O. Mortality and cancer incidence among workers in an abrasive manuand cancer incidence among workers in an abras

22 Eisen EA, Tolbert PE, Monson RR, Smith TJ. Mortality studies of machining fluid exposure in the automobile industry. I: a standardized mortality analysis. $A m \mathcal{F}$ Ind Med 1992:22:809-24.

23 International Agency for Research on Cancer. Wood dust and formaldehyde. Lyon: IARC, 1995:217-376. (IARC Monogr Eval Carcinog Risks Hum 62.)

24 Maier H, Fisher G, Sennewald E, Heller W-D. Berufliche Risikofaktoren für Rachenkrebs. Ergebnisse der Heidelberger Rachenkrebsstudie. HNO 1994:42:530-40.

25 Greenwald P. Prostate. In: Schottenfeld D, Fraumeni JF, eds. Cancer epidemiology and prevention. Philadelphia: WB eds. Cancer epidemiology

26 Pearce NE, Sheppard RA, Fraser J. Case-control study of occupation and cancer of the prostate in New Zealand. $\mathcal{F}$ occupation and cancer of the prostate in New

27 van der Gulden JJ, Kolk JJ, Verbeek, ALM. Prostate cancer and work environment. $\mathcal{F}$ Occup Med 1992;34:402-9.

28 Aronson KJ, Siemiatycki J, Dewar R, Gérin M. Occupational risk factors for prostate cancer: results from a case-control study in Montréal, Québec, Canada. Am $\mathcal{F}$ Epidemiol 1996;143:363-73.

29 Elghany NA, Schumacher MC, Slattery ML, West DW, Lee JS. Occupation, cadmium exposure, and prostate cancer. Epidemiology 1990;1:107-15.

30 Keller JE, Howe HL. Cancer in Illinois construction workers: a study. Am $\mathcal{F}$ Ind Med 1993;24:223-30. 